\title{
Geographic pattern of phytoplankton community and their drivers in lakes of middle and lower reaches of Yangtze River floodplain, ChinaGeographic pattern of phytoplankton community and their drivers in lakes of middle and lower reaches of Yangtze River floodplain, China
}

\section{Zhe Xiao}

Chinese Research Academy of Environmental Sciences

Hua Li

Chinese Academy of Sciences

Xiaochuang Li ( $\square$ lilinostocacean@163.com )

Chinese Academy of Environmental Sciences https://orcid.org/0000-0002-9007-7567

Renhui Li

Wenzhou University

Shouliang Huo

Chinese Research Academy of Environmental Sciences

Gongliang Yu

Chinese Academy of Sciences

\section{Research Article}

Keywords: Phytoplankton, MLYR floodplain lakes, Human pressure, Functional trait, Deterministic processes, Stochastic process

Posted Date: November 3rd, 2021

DOI: https://doi.org/10.21203/rs.3.rs-1045645/v1

License: (a) (1) This work is licensed under a Creative Commons Attribution 4.0 International License. Read Full License 


\section{Abstract}

Disentangling the relative contributions of deterministic and stochastic processes were critical to compressive understanding of underlying mechanism governing geographic pattern and assembly of phytoplankton community, while it was seldom performed in connected lakes under human pressure. Here, we investigated phytoplankton community pattern in relation to environmental and spatial factors over 81 lakes located in middle and lower reaches of Yangtze River (MLYR) floodplain, where many lakes suffered eutrophication and cyanobacterial blooms. A majority of MLYR lakes had higher phytoplankton abundance surpassing $10^{7}$ cells/L, and were dominated by common bloom-forming cyanobacterial genera, including Pseudanabaena, Microcystis, Merismopedia, Dolichospermum, Limnothrix, and Raphidiopsis. Phytoplankton community exhibited a striking geographical pattern both for taxonomic and functional compositions, while functional groups were less sensitive and disimmilarity in communities displayed no significant increases with increasing geographical distance. Further, species richness explained much higher percentage of community variations than species turnover, indicating a reduced effect of environmental filtering of phytoplankton species with tolerance to similar environments in connected MLYR lakes. Both deterministic and stochastic processes governed assembly and biogeographic of phytoplankton community. Variation partition analysis showed spatial factors exhibited greater influence on phytoplankton community compared to environmental variables. The stronger influence of spatial factors was further demonstrated by Mantel test and neutral community model. These findings indicate deterministic and stochastic processes exhibited similar biogeographic patterns for phytoplankton community in MLYR lakes, but stochastic process was overwhelmingly dominated. Moreover, a large proportion of unexplained variation implies complex interactions exist to shape assembly mechanism of phytoplankton community in MLYR lakes.

\section{Introduction}

Phytoplankton, a group of photosynthetic organisms with the size range from less than 2-200 $\mu \mathrm{m}$, contributing nearly half of primary production on the earth and playing a pivotal role in nutrient cycling, energy flow, and food web dynamics (Cardinale et al. 2002; Field et al. 1998). Phytoplanktons were sensitive to environmental changes, and have been widely demonstrated as an ideal bio-indicator for water quality assessment in a vast number of water bodies (Salmaso et al. 2006; Wu et al. 2019). In recent decades, anthropogenic inputs of excessive nutrients into lakes and reservoirs combined with global warming have resulted in recurrent blooms, and further a rapid loss of biodiversity, ecosystem integrity, and stability in freshwaters (Huisman et al. 2018; Sala et al. 2000; Vörösmarty et al. 2010). Understanding the ecological process and mechanism driving phytoplankton diversity and biogeographic pattern is hence of great importance to provide baseline information to develop sustainable strategies for the management and conservation of biodiversity.

Traditionally, local environments (deterministic process) have been concentrated as the main drivers for phytoplankton community assembly from the aspects of bottom-up control by resources (light and nutrients) and top-down control by zooplankton and fish (Reynolds 2006). This could be ascribed that phytoplanktons have small size and large population abundance that reduce extinction rate and increase dispersal probability, and are assumed to be not limited by dispersal and recognized as cosmopolitanisms (Padisák et al. 2016). Contrarily, the neutral theory challenged this view by assuming the interacting species are equivalent, and population dynamics are driving by random variation in births and deaths, of which dispersal ability are 
restricted by increasing geographical distance (stochastic process) (Hubbell 2001). A 25 years' survey in comparison with previous records of phytoplankton diversity covering 161 water bodies across $110,994 \mathrm{~km}^{2}$ in Bulgaria found 318 in 1,393 infrageneric taxa exhibited restricted spatial distribution (Stoyneva 2016). From metacommunity theory, a metacommunity is a set of local communities that are connected by dispersal of multiple potentially interacting species, suggesting environmental and spatial factors act together on shaping community structure and diversity (Leibold et al. 2004).

The metacommunity concept advances our understanding of the underlying mechanism that governs community assembly, and helps to explain how organisms are dispersed in a given region through quantifying the relative contributions of environmental and spatial factors (Mihaljevic 2012), based on different theoretical paradigms (species sorting, patch dynamics, mass effect and neutral model). Patch dynamics and mass effects are special cases of species sorting, emphasizing local processes; while neutral model assumes traits shared among species shows no difference and their population dynamics are driven by random losses and gains of species, focusing on regional processes (Winegardner et al. 2012). These four paradigms occupied not all of the inference of metacommunity theory for the mechanism structuring community assembly, meanwhile, they were not mutually exclusive (Brown et al. 2017; Winegardner et al. 2012).

In recent years, a growing number of studies have included space in the analysis, but came to inconsistent conclusions regarding the relative importance of deterministic and stochastic processes in shaping geographical distribution pattern of phytoplankton communities. Some authors found either spatial or environmental factors were the main drivers (Meier and Soininen 2014; Vanormelingen et al. 2008), while others demonstrated both these two factors played crucial roles in structuring community (Soininen et al. 2007). Nonetheless, some authors reported that neither environmental nor spatial factors explained a significant proportion of variations in phytoplankton community (Nabout et al. 2009). It was argued that the lack of inconsistent conclusions were reflected the differences in the spatial scale, the level of eutrophication, the strength of local environmental gradients, and the degree of connectivity among the studied freshwaters (Özkan et al. 2013; Soininen et al. 2011; Soininen 2014; Xiao et al. 2016). Taken the connectivity as an example, phytoplankton species were easily transported between connected waters, resulting in a homogenous community composition (Cottenie 2005). The connectivity reduced the filtering effects of local environmental conditions, while in isolated waters, dispersal was blocked and the effects of local processes overrode that of regional processes in determining phytoplankton community structure (Padisák et al. 2010).

The middle and lower reaches of the Yangtze River basin are featured as the typical floodplain in which many shallow lakes connect with each other through intricate river networks (Yin et al. 2007). Particularly in the wet season, the frequent change of regional water level induces a mutual hydrodynamic exchange among these lakes, finally resulting in spatial destructuring and limnological homogenization (Bai et al. 2020; Thomaz et al. 2007). The floodplain lakes provide a good system to test the metacommunity theory for these lakes that are highly dynamic ecosystems with a wide diversity of habitats, as well as in their degree of connectivity (Ward and Tockner 2001). Moreover, a number of lakes suffered eutrophication and cyanobacterial blooms in MLYR (Chen et al. 2020), therefore understanding the main drivers in structuring phytoplankton community in lakes under human pressure is vital for biodiversity conservation and sustainable watershed management. 
Until now, rare studies have investigated geographical distribution pattern of phytoplankton community structure in the largescale MLYR floodplain lakes, especially considering the relative roles of both spatial and environmental factors. In the study, we disentangled and quantified the contributions of deterministic and stochastic processes in structuring phytoplankton community in 81 lakes of MLYR floodplain during flooding period. Our main objectives were to: (i) uncover the geographical distribution and variation of phytoplankton community within and among MLYR floodplain lakes; (ii) identify the main drivers for phytoplankton community succession; (iii) disentangle the quantitative contributions of deterministic and stochastic processes for variations in phytoplankton community. Taken together, this research will enhance our understanding how phytoplankton communities were structured for the lakes with connectivity and human pressure, and will provide baseline information for biodiversity conservation and sustainable watershed management in MLYR floodplain lakes.

\section{Materials And Methods}

\section{Study area, sampling, environmental and spatial variables}

The middle and lower reaches of Yangtze River (MLYR) floodplain located in the subtropical climatic zone, with more than 600 lakes larger than $1 \mathrm{~km}^{2}$ distributed within the basin (Xu et al. 2017). The lakes played the pivotal role in both regional economic development and ecological stability (Cui et al. 2013). Heavy nutrients and other contaminants input from local and upstream areas have resulted in the deteriorated water quality, and most of these lakes were eutrophic even ecologically unbalanced (Qin 2002).

Surface water $(0.5 \mathrm{~m})$ was collected from 81 lakes within MLYR floodplain during August 2013 (Fig.1). Between 3 and 30 sampling sites for each lake were designed depending on the lake area (Table S1). The eutrophication indicators (SD, cholophyll-a, TN and TP) and water surface temperature $(T)$ were averaged with monthly monitoring data on August 2013 from China National Environmental Monitoring Centre and provincial environmental monitoring stations (Fig. S1, Table S1). The information on the lake morphological characteristics (depth, area, capacity), and the climate dataset (precipitation) were obtained from published research articles (Table S1). The hydrodynamics (hydraulic retention time, HRT) was defined:

HRT $=365($ days $) *$ capacity / annual runoff

where capacity = lake area * lake mean depth, annual runoff = surface collecting area * precipitation * runoff coefficient (Shi et al. 2018). For the spatial component, the principal coordinates of neighbor matrices (PCNMs) analysis was performed with the vegan package to calculate a set of spatial variables based on the longitude and latitude coordinates of center of each lake (Oksanen et al. 2013).

\section{Morphological identification and functional groups}

For phytoplankton diversity analyses, $1 \mathrm{~L}$ freshwater was immediately fixed with $1.5 \%$ Lugol's iodine solution in situ, and then transported to the laboratory for species identification (Izaguirre et al. 2016). Phytoplankton species were identified by $400 \times$ magnification under microscope (Nikon, Japan), and at least 500 cells were counted for each sample. Morphological identification followed the nomenclature by Hu and 
Wei (2006). The species identified by morphology were further merged into functional groups using the criteria of Reynolds et al. (2002) and Padisák et al. (2009), which were grouped by similar ecophysiological adaptations to environmental constraints.

\section{Community diversity and structure}

Sampling sites with observed phytoplankton species $<10$ were abandoned. Then, phytoplankton species abundance averaged from sampling sites within a lake obtained phytoplankton community composition and structure of each lake. Community diversity, including the number of species, Shannon-Wiener and Simpson diversities, and Pielou evenness were calculated using PRIMER v.7.0 (Clarke and Gorley 2015). Beta-diversity was estimated based on Bray-Curtis dissimilarity of community diversity and abundance. Beta-diversity was further partitioned into two components as species richness and species turnover that represented the balanced variation and abundance gradient, respectively. The partition was implemented using the bray.part function of the betapart R package (Jiao et al. 2017).

Non-metric multidimensional scaling (NMDS) analysis was used to reveal geographical pattern of phytoplankton community among lakes located in different provinces. Analysis of similarity (ANOSIM) was used to investigate significant differences in phytoplankton communities between set groups. The global $R$ in ANOSIM analysis ranges from 0 to 1 that represents community separation degree between groups, with $R=0$ indicating no separation and $R=1$ as complete separation. NMDS and ANOSIM analyses were all performed with PRIMER v.7.0 (Clarke and Gorley 2015).

\section{Relationships between phytoplankton community and environmental and spatial variables}

To explore the potential impacts of environmental and spatial variables, the relationships between Bray-Curtis dissimilarity of phytoplankton community and Euclidean distance of local environments and geographic distance were analyzed based on Spearman's rank correlations. Before analysis, environmental variables and phytoplankton abundance were $\log (x+1)$ and fourth root transformed, respectively, to improve homoscedasticity and normality for multivariate statistical analyses (Lepš and Šmilauer 2003).

The longest gradient lengths of detrended correspondence analysis (DCA) were $<3$ for both taxonomic compositions and functional groups of phytoplankton community, redundancy analysis (RDA) was then selected to investigate the relationships between phytoplankton community and environmental and spatial variables. Before RDA analysis, environmental and spatial variables exhibited high variance inflation factor $(\mathrm{VIF}) \otimes 20$ were eliminated to avoid collinearity among factors. A forward selection was performed to select those significant explanatory variables for further analysis (Blanchet et al. 2008). Then, variation partitioning analysis (VPA) was used to quantify the relative contributions of environmental and spatial variables in shaping community composition with adjusted $R^{2}$ coefficients based on RDA analysis (Peres-Neto et al. 2006). The explained contributions of environmental and spatial factors included environmental variables (E), pure environmental variables (EIS), spatial variables (S), pure spatial variables (S|E), and the combined effects of environmental and spatial variables. The residual proportion represented unexplained variance by explanatory environmental and spatial variables. 
Several studies based on simulation models have shown VPA failed to correctly predict the environmental and spatial inference of community structure (Gilbert and Bennett 2010), thus Mantel test and partial Mantel tests were conducted to assess the relationships between phytoplankton community variations and environmental/spatial variables. VPA and Mantel tests were combined to assess and verify the relative importance of environmental and spatial variables. Mantel tests were realized by the vegdist and mantel function of vegan R package, and RDA and VPA analyses were performed with Canoco version 4.5.

\section{Neutral community model}

Sloan's community model was used to assess the potential importance of stochastic process for phytoplankton community (Sloan et al. 2006). The model predicts the relationship between the observed species frequency in a set of local communities and their regional relative abundance across the wider metacommunity, and could reflect the adaptation of neutral theory that was adjusted to be suitable for large microbial populations (Hubbell 2001). In the model, the parameter $R^{2}$ determines the overall fit to the neutral model. The parameter $N m$ determines the correlation between occurrence frequency and regional relative abundance, with $N$ and $m$ describing the metacommunity size and immigration rate, respectively (Sloan et al. 2006). The neutral model was run in MicEco R package.

\section{Result}

\section{Taxonomic and functional diversity of phytoplankton community}

A total of 397 infrageneric taxa from 8 phytoplankton phyla were identified in MLYR floodplain lakes, including Cyanophyta, Chlorophyta, Bacillariophyta, Euglenophyta, Cryptophyta, Dinophyta, Chrysophyta, and Xanthophyta. Chlorophyta was most diverse with 174 infrageneric taxa being detected, followed by Bacillariophyta (94), Cyanophyta (70), and Euglenophyta (27), with 32 infrageneric taxa in the other 5 phyla. Jiangsu Province exhibited the highest phytoplankton diversity, while Hubei and Jiangxi provinces presented the lowest diversity, basing on the evaluation of the number of species, Simpson and Shannon-Wiener diversity indices. As well, Hubei Province showed the lowest Pielou evenness index, whereas in Hunan and Anhui provinces, they displayed the highest evenness diversity (Fig. S2).

A contrasting variation of phytoplankton abundance was found in different lakes along the MLYR floodplain. In Jiangsu, Hubei, Hunan, and Jiangxi provinces, total phytoplankton abundance of a majority lakes surpassed $10^{7}$ cells/L, or even higher than $10^{8}$ cells/L; however, in Anhui Province, lakes exhibited a relatively lower abundance than $10^{7}$ cells/L (Fig. S3). The phytoplankton community composition showed some links to the abundance in lakes. In Jiangsu, Hubei, Hunan, and Jiangxi provinces, Cyanophyta was overwhelmingly dominant over other phytoplankton phyla in all lakes, except some lakes in Hubei Province where phytoplankton abundance was lower than $10^{7}$ cells/L, and Cyanophyta and Chlorophyta co-dominated in the lakes (Fig. S4). In Anhui Province, lakes were dominated either by Cyanophyta, Chlorophyta, Bacillariophyta, or combinations of these phytoplankton phyla (Fig. S4). In total, 44 infrageneric taxa showed wide distributions found in over 1/3 MLYR lakes. Amongst, Pseudanabaena, Microcystis, and Merismopedia were the most dominant for they had a mean abundance of $10^{7}$ cells/L over the whole 81 lakes; followed by Dolichospermum, Limnothrix, and Raphidiopsis, they had a mean abundance of $10^{6}$ cells/L (Fig. 2a). 
Altogether, 29 functional groups (FGs) were identified in MLYR floodplain lakes. Similar to phytoplankton diversity of taxonomic compositions, Jiangsu Province exhibited the highest functional diversity, while Hubei and Jiangxi provinces presented the lowest diversity. For Simpson evenness index, we came to the same result that Hunan and Hubei Provinces showed the highest and lowest evenness diversity, respectively (Fig. S5). A total of $19 \mathrm{FGs}$ exhibited a wide distributions in over 1/3 MLYR floodplain lakes, amongst FGs belonging to Lo, $\mathrm{S} 1$, and $\mathrm{M}$ showed the high mean of phytoplankton abundances over $10^{7}$ cells/L, and FGs attributed to $\mathrm{SN}, \mathrm{J}$, $H 1, M P, T, D, T c, P$, and S2 had the mean abundances over $10^{6}$ cells/L in MLYR floodplain lakes (Fig. 2b).

\section{Geographical distribution pattern of phytoplankton community}

We observed a more or less separation of phytoplankton community in the lakes among different provinces along the MLYR floodplain, both for taxonomic and functional compositions (Fig. 3). The phytoplankton community in Hubei lakes distributed randomly, and had a low separation from that in lakes of other provinces. This was demonstrated by ANOSIM analysis that community separation was significant compared with lakes from different provinces, except comparisons between Hubei and other provinces, moreover this was particularly evident for functional groups (Table 1).

Dissimilarity in phytoplankton community increased with increasing geographical distance (Fig. S6a-b), while the positive correlations were significant for taxonomic composition $(R=0.098, P=0.024)$ but not for functional groups $(R=0.061, P=0.114)$. Beta-diversity partitioning revealed that species richness (nestedness) rather than species replacement (turnover) contributed to the majority of the beta-diversity and drove the community changes over geographical distance, for both taxonomical and functional compositions (Fig. S6c-d). Species richness displayed a significant increase with distance for taxonomic composition ( $R=0.098, P=0.024)$, but their correlations were not evident for functional composition $(R=0.042, P=0.193)$.

\section{Environmental and spatial factors related to patterns of phytoplankton community}

We explored the balance between deterministic and stochastic selections in structuring biogeographic pattern of phytoplankton community in MLYR floodplain lakes, including physical (temperature), eutrophication indicators (SD, TN and TP), lake morphological characteristics (depth, area, capacity), hydrodynamics (water retention time), the climate (precipitation) and spatial factors (PCNMs). Inferred from RDA ordination plot, only spatial factors (PCNMs 2-5) were significantly related to taxonomic compositions (Fig. 4a), while for functional compositions, both environmental (TP and precipitation) and spatial (PCNMs 3 and 5) contributed to the significant changes of communities (Fig. 4b).

The Mantel tests indicated spatial effects exhibited more influential impacts than environmental variables in structuring phytoplankton community in the whole MLYR lakes, both for taxonomic and functional compositions (Table 2). PCNM1 and PCNM2 showed significant correlations with communities, while all of environmental factors had minor influences. At provincial scales, local environments played the pivotal role in structuring phytoplankton communities, both for taxonomic and functional compositions, especially for those in Jiangsu and Hunan lakes, whereas spatial selections displayed less influential impacts (Table 2).

VPA analysis revealed the similar results for taxonomic and functional compositions of phytoplankton community changes explained by environmental and spatial factors. For taxonomic compositions, the pure 
spatial variables (24.0\%) explained a much higher proportion of community variation than that by pure environmental variables (3.0\%) (Fig. 5a). As well, the pure spatial variables (23.5\%) exhibited a higher explanation than by pure environmental variables (3.1\%) for functional composition (Fig. 5b). The shared explanations by jointly environmental and spatial factors were almost equal to purely environmental variables. The strong effects of spatial factors were further demonstrated by the neutral community model (NCM). NCM assessed the potential importance of neutral processes of phytoplankton community, and explained a large fraction of variations both for taxonomic $\left(R^{2}=0.834\right)$ and functional $\left(R^{2}=0.732\right)$ compositions (Fig. S7).

\section{Discussion}

\section{Phytoplankton community exhibited evident biogeographic patterns in MLYR floodplain lakes}

With the rapid population increase and economic growth in MLYR floodplain, intensive anthropogenic activities brought excessive nutrients into lakes that resulted in water quality deterioration (Feng et al. 2019; Luo et al. 2019). Using MERIS and OLCI remote sensing images to retrieve chlorophyll-a concentrations, all 50 examined large lakes in MLYR floodplain presented high probabilities of eutrophication (Guan et al. 2020). This was further demonstrated in our study that a majority of MLYR floodplain lakes exhibited a much higher phytoplankton abundance surpassing $10^{7}$ cells/L, or even higher than $10^{8}$ cells/L (Fig. S3). In these lakes, the common bloom forming cyanobacteria Pseudanabaena, Microcystis, Merismopedia, Dolichospermum, Limnothrix, and Raphidiopsis were predominant (Fig. 2a), suggesting MLYR shallow lakes would be highly susceptible to cyanobacterial blooms. These dominant genera were affiliated to FGs as Lo, S1, and $\mathrm{M}$ that were favored by turbid, eutrophic and a high irradiance conditions (Fig. 2b), which were characteristics of shallow lakes (Reynolds et al. 2002).

The MLYR floodplain constitutes a network of shallow lakes with different connectivity degrees, and allowed the exchange of hydrodynamics via watercourses in the wet season, resulting an increased habitat similarity (Devercelli et al. 2016). Similarly, local environments exhibited not distinct differences among lakes from different provinces in MLYR floodplain (Fig. S8). Different species had their own properties, such as physiological tolerances and dispersal abilities, and the similar environments might result in a final homogenization of phytoplankton communities. However, we found a striking geographical pattern of phytoplankton community among lakes of different provinces in MLYR floodplain (Fig. 3). Though flooding generated the similar environments in connected lakes, yet it took time to facilitate dispersal among lakes, thus spatial patterns existed in the previous period were still present during the flooding period (Rojo et al. 2016). Furthermore, Euclidean distance of environments showed significant increases with geographical distance (Fig. S9). The MLYR lakes were connected to some degrees, inland lakes were separated by dry land, and hydrodynamic gradients existed among these lakes (Bai et al. 2020). Additionally, a large number of dams built for reservoirs and flood control also acted as the barriers for the exchange of hydrodynamics among lakes. By the year of 2009, over 47,000 dams have been built in the Yangtze River basin (Wang et al. 2019). Contrarily, bacterioplankton community tended to cluster together in the lakes with small distance in MLYR floodplain (Bai et al. 2020). Bacterioplanktons in Jiangsu lakes shared high similarities, but exhibited significant dissimilarities from those in Anhui, Jiangxi, and Hubei lakes. The discrepant results were explained that decreasing size increased the dispersal rate of passively dispersing species, thus larger phytoplanktons exhibited more spatial limitation than by smaller bacterioplanktons (Beisner et al. 2006; Mazaris et al. 2010). 
Beta-diversity linked local and regional diversity by measuring the amount of species dissimilarity between communities, and played a pivotal role in disentangling the various processes that shaped biodiversity patterns across scales (Viana et al. 2015). Beta-diversity could be further divided into two components: species richness represented that local communities were formed by subsets of species from regional communities, while species turnover indicated one species was substituted by another, or the changes of its relative abundance in the community among sites (Ulrich et al. 2009; Yang et al. 2018). In MLYR floodplain lakes, beta-diversity partitioning revealed that species richness rather than species turnover governed the assembly and biogeographic pattern of phytoplankton community structure (Fig. S6c-d). As shown in isolated freshwaters and freshwaters with contrasting environmental gradients, spatially structured environmental filtering induced the high species replacement, mediated by species properties adapted to different environments (Vanormelingen et al. 2008; Yang et al. 2018). Among interconnected lakes, matters and hydrodynamics were exchanged through watercourses that resulted in increased habitat similarity (Thomaz et al. 2007), in addition, hydrodynamics exhibited not significant differences in the floodplain lakes (Bai et al. 2020), reduced the effect of environmental filtering of phytoplankton species with the tolerance to these similar environments. Moreover, spatial isolation could increase the relative importance of species richness and reduce the contributions of species turnover (Bender et al. 2016). The studied 81 connected lakes spanned an intermediate scale over 1000 $\mathrm{km}$, highlighting the importance of spatial factors in structuring phytoplankton communities in the MLYR floodplain, and their relative contributions were further discussed below.

\section{Stochastic processes contributed over deterministic processes in governing phytoplankton community}

Metacommunity theory suggested both environmental and spatial factors shape community structure and diversity (Leibold et al. 2004). Due to their small size, and rapid and complex responses to environmental changes of phytoplankton species, it was difficult to divide the relative contributions of environmental and spatial variables (Etienne and Alonso 2007). The geographical distance has been used for measuring the dispersal abilities in shaping microbial communities (Melo et al. 2011), and the relative importance of dispersal could be further demonstrated by the distance decay pattern between community and geographical distance (Chen et al. 2017), and neutral model (Sloan et al. 2006). Phytoplankton community displayed a significant distance decay pattern with increasing geographic distance (Fig. S6a), strengthening the important role of spatial factors in structuring phytoplankton communities in MLYR floodplain lakes. With the increasing scales, the dispersal capabilities of organisms were limited, and the environmental gradients induced by dry lands among lakes acted as filters that could not fulfill their niche requirements (Soininen 2012). The functional compositions of phytoplankton community showed a less evident and decreased distance decay pattern than by taxonomic compositions (Fig. S6a-b). Functional groups were composed of set of species that shared common physiological and ecological traits (Padisák et al. 2009; Reynolds et al. 2002), and reflected more sensitive responses to environmental gradients than by taxonomic compositions, thus resulting in much higher dispersal limitations with increasing distance scales. It could be expected functional groups exhibit a more evident distance decay pattern than by taxonomic compositions for phytoplankton community, while we got the adverse results in MLYR floodplain lakes (Fig. S6a-b). Connected lakes in MLYR floodplain lakes exchanged matters and organisms that resulted in the increased habitat similarity and a homogenization of phytoplankton community might complicate these processes. 
The neutral model has been widely used to quantify the relative importance of stochastic processes, and could correctly explain microbial community assembly and pattern in diverse environments (Roguet et al. 2015). The neutral model explained a large proportion of overall fits to the neutral model, further demonstrated the pivotal role of spatial factors in governing phytoplankton communities (Fig. S7). As we expected, the explained variations of taxonomic $\left(R^{2}=0.834\right)$ compositions were higher than that by functional groups $\left(R^{2}=0.732\right)$, further demonstrating spatial variables had more influential effects on taxonomic compositions than functional groups.

Previous studies concluded that both deterministic and stochastic processes governed the assembly and biogeographic pattern of phytoplankton community in aquatic systems (Devercelli et al. 2016; Guo et al. 2019; Izaguirre et al. 2016; Moresco et al. 2017; Rojo et al. 2016; Santos et al. 2016; Soininen et al. 2007; Yang et al. 2018). It was argued that the relative role of deterministic and stochastic processes was related to the sampling scale (Izaguirre et al. 2016). At small scales (few kilometers), phytoplanktons with highly passive dispersal abilities were easily transferred from one site to another, and local environments acted as the only filters for species. With the spatial scales increasing, geographical distance as barriers blocked their dispersal and led to a combination of both environmental and spatial constraints. At a wide spatial scale (tens of thousands of kilometers), the effects of regional processes overrode that of local processes in governing phytoplankton community. The MLYR lakes spanned an intermediate scale over $1000 \mathrm{~km}$, bias was obtained by Mantel tests that only spatial factors influenced the geographic pattern of phytoplankton communities (Table 2). Consistent with previous assumptions (Izaguirre et al. 2016), at provincial scales (small scales), local environments predominated over spatial variables in structuring phytoplankton communities (Table 2).

The biased results at regional scales in MLYR lakes were also observed in RDA analysis that only spatial variables were significantly related to taxonomic compositions of phytoplanktons (Fig. 4). VPA analysis further demonstrated spatial variables contributed a larger proportions over local environments in structuring phytoplankton communities in MLYR floodplain lakes (Fig. 5). Several explanations could account for the overwhelmingly superiority of spatial variables. First, as mentioned above, the studied 81 connected lakes spanned an intermediate scale over $1000 \mathrm{~km}$ in the MLYR floodplain, indicating a combination of both stochastic and deterministic processes involved in the assembly of phytoplankton community structure (Soininen 2012). Second, shallow lakes in MLYR floodplain connected in the wet season, and exchanged hydrodynamics and organisms through watercourse among these lakes. The connectivity reduced the filtering effects of local environmental conditions, and finally resulted in a homogenization of phytoplankton communities in MLYR floodplain lakes (Cottenie 2005). Third, the disordered interconnectivity among lakes without hydrological bias increased the random distribution of species distribution (Bai et al. 2020), further supporting a wide distribution of phytoplankton species in MLYR floodplain lakes. Last but not least, the stochastic process overwhelmed deterministic process when abundant bacterial species were generalists in various habitats (Liu et al. 2015; Wang et al. 2013). In MLYR floodplain lakes, 44 infrageneric phytoplankton taxa showed wide distributions found in over $1 / 3$ lakes (Fig. 2a), suggesting these generalists contribute to the overwhelming superiority of stochastic process over deterministic process in governing geographic pattern of phytoplankton community in MLYR floodplain lakes.

\section{Conclusion}

Page $10 / 20$ 
In the study, both deterministic and stochastic processes drove the geographical pattern of phytoplankton community structure in MLYR floodplain lakes, although their relative contributions were different. However, spatial variables explained more community variation than by environmental factors for connected lakes in MLYR floodplain exchanged matters and organisms and resulted in the increased habitat similarity and homogenization of phytoplankton community. Though important local environments (TN and TP) were included, the explained variation by environmental variables was much low. Therefore, to protect MLYR floodplain lakes under human pressure, both local environmental conditions and the effect of regional phytoplankton species pool on local community should be considered. Our findings enhance the mechanistic understanding of geographic pattern of phytoplankton community among interconnected lakes under human pressure, and have important implications for biodiversity conservation and ecosystem function in these connected and eutrophicated lakes.

\section{Declarations}

Ethics approval and consent to participate Not applicable.

Consent for publication Not applicable.

Author's contributions Zhe Xiao: Data analysis, writing; Hua Li: Data acquisition, writing-review and editing; Xiao-Chuang Li: Conceptualization, methodology, project administration, writing, writing-review and editing; RenHui Li: Data acquisition, writing-review and editing; Shou-Liang Huo: Conceptualization, methodology, project administration, writing-review and editing; Gong-Liang Yu: Data acquisition, writing-review and editing.

Funding The research was funded by the Mega-projects of Science Research for Water Environment Improvement (Program No. 2012ZX07101-002) and the National Science Foundation for Young Scientists of China (No. 31700404).

Competing interest The authors declare no conflict of interest with the research article.

Availability of data The eutrophication indicators, lake morphological characteristics, climate and hydrodynamics dataset were available in Table S1. Phytoplankton dataset are available from the corresponding author (lilinostocacean@163.com) upon reasonable request.

\section{References}

Bai CR, Cai J, Zhou L, Jiang XY, Hu Y, Dai JY, Shao KQ, Tang XM, Yang XD, Gao G (2020) Geographic patterns of bacterioplankton among lakes of the middle and lower reaches of the Yangtze River Basin, China. Appl Environ Microb 86(6):e02423-19.

Beisner BE, Peres-Neto PR, Lindström ES, Barnett A, Longhi ML (2006) The role of environmental and spatial processes in structuring lake communities from bacteria to fish. Ecology 87(12):2985-2991.

Bender MG, Leprieur F, Mouillot D, Kulbicki M, Parravicini V, Pie MR, Barneche DR, Oliveira-Santos GR, Floeter SR (2016) Isolation drivers taxonomic and functional nestedness in tropical reef fish faunas. Ecography 40(3):425435. 
Blanchet FG, Legendre P, Borcard D (2008) Forward selection of explanatory variables. Ecology 89:2623-2632.

Brown BL, Sokol ER, Skelton J, Tornwall B (2017) Making sense of metacommunities: dispelling the mythology of a metacommunity typology. Oecologia 183:643-652.

Cardinale BJ, Palmer MA, Collins SL (2002) Species diversity enhances habitat

functioning through interspecific facilitation. Nature 415(6870):426-429.

Chen Q, Huang M, Tang X (2020) Eutrophication assessment of seasonal urban lakes in China Yangtze River basin using Landsat 8-derived Forel-Ule index: a six-year (2013-2018) observation. Sci Total Environ 745:135392.

Chen W, Pan Y, Yu L, Yang J, Zhang W (2017) Patterns and processes in marine microeukaryotic community biogeography from Xiamen coastal waters and intertidal sediments, southeast China. Front Microbiol 8:1912.

Clarke KR, Gorley RN (2015) PRIMERv7: User Manual/Tutorial PRIMER-E, Plymouth.

Cottenie K (2005) Integrating environmental and spatial processes in ecological community dynamics. Ecol Lett 8:1175-1182.

Cui L, Gao C, Zhao X (2013) Dynamics of the lakes in the middle and lower reaches of the Yangtze River basin, China, since late nineteenth century. Environ Monit Assess 185:4005-4018.

Devercelli M, Scarabotti P, Mayora G, Schneider B, Giri F (2016) Unravelling the role of determinism and stochasticity in structuring the phytoplanktonic metacommunity of the Paraná River floodplain. Hydrobiologia 764(1):139-156.

Etienne RS, Alonso D (2007) Neutral community theory: how stochasticity and dispersal-limitation can explain species coexistence. J Stat Phys 128:485-510.

Feng L, Hou X, Zheng Y (2019) Monitoring and understanding the water transparency changes of fifty large lakes on the Yangtze Plain based on long-term MODIS observations. Remote Sens Environ 221:675-686.

Field CB, Behrenfeld MJ, Randerson JT, Falkowski P (1998) Primary production of the biosphere: integrating terrestrial and oceanic components. Science 281:237-242.

Gilbert B, Bennett JR (2010) Partitioning variation in ecological communities: do the numbers add up? J Appl Ecol 47:1071-1082.

Guan Q, Feng L, Hou X, Schurgers G, Zheng Y, Tang J (2020) Eutrophication changes in fifty large lakes on the Yangtze Plain of China derived from MERIS and OLCI observations. Remote Sens Environ 246:111890.

Hu HJ, Wei YX (2006) Chinese freshwater algae-system, classification and ecology. Science Press, Beijing, China.

Hubbell SP (2001) A unified neutral theory of biodiversity and biogeography. 
Princeton University Press, Princeton, New Jersey, USA.

Huisman J, Codd GA, Paerl HW, Ibelings BW, Verspagen JM, Visser PM (2018) Cyanobacterial blooms. Nat Rev Microbiol 16(8):471-483.

Izaguirre I, Saad JF, Schiaffino MR, Vinocur A, Tell G, Sánchez ML, Allende L, Sinistro R (2016) Drivers of phytoplankton diversity in Patagonian and Antarctic lakes across a latitudinal gradient (2150 km): the importance of spatial and environmental factors. Hydrobiologia 764:157-170.

Jiao S, Chen WM, Wei GH (2017) Biogeography and ecological diversity patterns of rare and abundant bacteria in oil-contaminated soils. Mol Ecol 26:5305-5317.

Legendre P, Borcard D, Peres-Neto PR (2008) Analyzing or explaining beta diversity? Comment Ecology 89:32383244.

Leibold MA, Holyoak M, Mouquet N, Amarasekare P, Chase JM, Hoopes, MF, Holt RD, Shurin JB, Law R, Tilman D et al (2004) The metacommunity concept: a framework for multi-scale community ecology. Ecol Lett 7:601-613.

Lepš J, Šmilauer P (2003) Multivariate analysis of ecological data using CANOCO. Cambridge University Press, Cambridge, United Kingdom.

Liu LM, Yang J, Yu Z, Wilkinson DM (2015) The biogeography of abundant and rare bacterioplankton in the lakes and reservoirs of China. ISME J 9:2068-2077.

Luo Q, Luo L, Zhou Q, Song Y (2019) Does China's Yangtze River Economic Belt policy impact on local ecosystem services? Sci Total Environ 676:231-241.

Mazaris AD, Moustaka-Gouni M, Michaloudi E, Bobori DC (2010) Biogeographical patterns of freshwater microand macroorganisms: a comparison between phytoplankton, zooplankton and fish in the eastern Mediterranean. J Biogeogr 37(7):1341-1351.

Meier S, Soininen J (2014) Phytoplankton metacommunity structure in subarctic rock pools. Aquat Microb Ecol 73:81-91.

Melo AS, Schneck F, Hepp LU, Simões NR, Siqueira T, Bini LM (2011) Focusing on variation: methods and applications of the concept of beta diversity in aquatic ecosystems. Acta Limnologica Brasiliensia 23:318-331.

Mihaljevic JR (2012) Linking metacommunity theory and symbiont evolutionary ecology. Trends Ecol Evol $27(6): 323-329$.

Nabout JC, Siqueira T, Bini LM, de Nogueira IS (2009) No evidence for environmental and spatial processes in structuring phytoplankton communities. Acta Oecol 35:720-726.

Oksanen J, Blanchet FG, Kindt R, Legendre P, Minchin R, O'Hara RB, Oksanen J, Blanchet FG, Kindt R, Legendre P et al (2013) Vegan: community ecology package R package version 2.0-10. 
Özkan K, Jeppesen E, Søndergaard M, Lauridsen TL, Liboriussen L, Svenning JC (2013) Contrasting roles of water chemistry, lake morphology, land-use, climate and spatial processes in driving phytoplankton richness in the Danish landscape. Hydrobiologia 710:173-187.

Padisák J, Crossetti L, Naselli-Flores L (2009) Use and misuse in the application of the phytoplankton functional classification: a critical review with updates. Hydrobiologia 621(1):1-19.

Padisák J, Hajnal E, Naselli-Flores L, Dokulil MT, Nõges P, Zohary T (2010) Convergence and divergence in organization of phytoplankton community under various of physical and biological control. Hydrobiologia 639:205-220.

Padisák J, Vasas G, Borics G (2016) Phycogeography of freshwater phytoplankton: traditional knowledge and new molecular tools. Hydrobiologia 764:3-27.

Peres-Neto PR, Legendre P, Dray S, Borcard D (2006) Variation partitioning of species data matrices: estimation and comparison of fractions. Ecology 87:2614-2625.

Qin B (2002) Approaches to mechanisms and control of eutrophication of shallow lakes in the middle and lower reaches of the Yangze River. J Lake Sci 14:193-202.

Reynolds CS (2006) Ecology of phytoplankton. Cambridge University Press, Cambridge, United Kingdom.

Reynolds CS, Huszar V, Kruk C, Naselli-Flores L, Melo S (2002) Towards a functional classification of the freshwater phytoplankton. J Plankton Res 24(5):417-428.

Roguet A, Laigle GS, Therial C, Bressy A, Soulignac F, Catherine A, Lacroix G, Jardillier L, Bonhomme C, Lerch TZ et al (2015) Neutral community model explains the bacterial community assembly in freshwater lakes. FEMS Microbiol Ecol 91(11):1-11.

Rojo C, Mesquita-Joanes F, Monros JS, Armengol J, Sasa M, Bonilla F, Rueda R, Benavent-Corai J, Piculo R, Segura MM et al (2016) Hydrology affects environmental and spatial structuring of microalgal metacommunities in tropical Pacific coast wetlands. PLoS One 11(2):e0149505.

Sala OE, Chapin FS, Armesto JJ, Berlow E, Bloomfield J, Dirzo R, Huber-Sanwald E, Huenneke LF, Jackson RB, Kinzig A (2000) Global biodiversity scenarios for the year 2100. Science 287:1770-1774.

Salmaso N, Morabito G, Buzzi F, Garibaldi L, Simona M, Mosello R (2006) Phytoplankton as an indicator of the water quality of the deep lakes south of the Alps. Hydrobiologia 563(1):167-187.

Shi K, Zhang YL, Zhou YQ, Qin BQ, Zhang YB (2018) A method for calculating the water changing period of lakes (patent). Grant number: 108428057, China.

Sloan WT, Lunn M, Woodcock S, Head IM, Nee S, Curtis TP (2006) Quantifying the roles of immigration and chance in shaping prokaryote community structure. Environ Microbiol 8:732-740.

Soininen J (2012) Macroecology of unicellular organisms-patterns and process. Env Microbiol Rep 4:10-22. 
Soininen J (2014) A quantitative analysis of species sorting across organisms and ecosystems. Ecology 95:3284-3292.

Soininen J, Korhonen JJ, Karhu J, Vetterli A (2011) Disentangling the spatial patterns in community composition of prokaryotic and eukaryotic lake plankton. Limnol Oceanogr 56(2):508-520.

Soininen J, McDonald R, Hillebrand H (2007) The distance decay of similarity in ecological communities. Ecography 30:3-12.

Stoyneva MP (2016) Allochthonous planktonic algae recorded during the last 25 years in Bulgaria and their possible dispersal agents. Hydrobiologia 764(1):53-64.

Thomaz SM, Bini LM, Bozelli RL (2007) Floods increase similarity among aquatic habitats in river-floodplain systems. Hydrobiologia 579:1-13.

Ulrich W, Almeida-Neto M, Gotelli N (2009) A consumer's guide to nestedness analysis. Oikos 118:3-17.

Vanormelingen P, Cottenie K, Muchels E, Muylaert K, Vyverman W, de Meester L (2008) The relative importance of dispersal and local processes in structuring phytoplankton communities in a set of highly interconnected ponds. Freshwater Biol 53:2170-2183.

Viana DS, Figuerola J, Schwenk K, Manca M, Hobaek A, Mjelde M, Preston CD, Gornall RJ, Croft JM, King RA (2015) Assembly mechanisms determining high species turnover in aquatic communities over regional and continental scales. Ecography 39(3):281-288.

Vörösmarty CJ, Mclntyre PB, Gessner MO, Dudgeon D, Prusevich A, Green P, Glidden S, Bunn SE, Sullivan CA, Liermann CR (2010) Global threats to human water security and river biodiversity. Nature 467:555-561.

Ward JV, Tockner K (2001) Biodiversity: towards a unifying theme for river ecology. Freshwater Biol 46:807-819.

Wang HZ, Liu XQ, Wang HJ (2019) The Yangtze River-floodplain ecosystem: multiple threats and holistic conservation. Acta Hydrobiologica Sinica 43:157-182.

Winegardner AK, Jones BK, Ng ISY, Siqueira T, Cottenie K (2012) The terminology of metacommunity ecology. Trends Ecol Evol 27(5):253-254.

Wu Z, Kong M, Cai Y, Wang X, Li K (2019) Index of biotic integrity based on phytoplankton and water quality index: do they have a similar pattern on water quality assessment? A study of rivers in Lake Taihu Basin, China. Sci Total Environ 658:395-404.

Xiao LJ, Hu R, Peng L, Lei LM, Feng Y, Han BP (2016) Dissimilarity of phytoplankton assemblages in two connected tropical reservoirs: effects of water transportation and environmental filtering. Hydrobiologia 764(1):127-138.

Xu M, Dong X, Yang X (2017) Recent sedimentation rates of shallow lakes in the middle and lower reaches of the Yangtze River: patterns, controlling factors and implications for lake management. Water 9:617-618. 
Yang Y, Hu R, Lin Q, Hou J, Liu Y, Han BP, Naselli-Flores L (2018) Spatial structure and ß-diversity of phytoplankton in Tibetan Plateau lakes: nestedness or replacement? Hydrobiologia 808(1):301-314.

Yin H, Liu G, Pi J, Chen G, Li C (2007) On the river-lake relationship of the middle Yangtze reaches. Geomorphology 85:197-207.

\section{Tables}

Table 1 Pairwise comparison of phytoplankton communities in lakes located in different provinces along the MLYR floodplain based on one-way ANOSIM test

\begin{tabular}{lcccc}
\hline & \multicolumn{2}{c}{ Taxonomy } & \multicolumn{2}{c}{ Functional groups } \\
\cline { 2 - 5 } Groups & $R$ & $P$ & $R$ & $P$ \\
\hline Jiangsu vs Hubei & 0139 & 0031 & 004 & 0277 \\
\hline Jiangsu vs Hunan & 0596 & 0001 & 0338 & 0001 \\
\hline Jiangsu vs Jiangxi & 0861 & 0001 & 048 & 0001 \\
\hline Jiangsu vs Anhui & 0635 & 0001 & 0393 & 0001 \\
\hline Hubei vs Hunan & -0054 & 0678 & -0143 & 0936 \\
\hline Hubei vs Jiangxi & 0255 & 0007 & 0157 & 0072 \\
\hline Hubei vs Anhui & 0309 & 0001 & 0407 & 0001 \\
\hline Hunan vs Jiangxi & 0859 & 0001 & 0626 & 0001 \\
\hline Hunan vs Anhui & 0643 & 0001 & 0549 & 0001 \\
\hline Jiangxi vs Anhui & 055 & 0001 & 0446 & 0001 \\
\hline
\end{tabular}

Note: An R-statistic less than 0 represents complete random grouping Significant comparisons are marked in bold

Table 2 Mantel tests for the correlations between phytoplankton community and local environmental and spatial variables using Spearman coefficient

\begin{tabular}{|c|c|c|c|c|c|c|c|c|c|c|c|c|}
\hline & \multicolumn{6}{|c|}{ Taxonomy } & \multicolumn{6}{|c|}{ Function } \\
\hline & Total & Jiangsu & Hubei & Hunan & Jiangxi & Anhui & Total & Jiangsu & Hubei & Hunan & Jiangxi & Anhui \\
\hline WT & -0011 & -0041 & -0067 & -0086 & 0358 & 0097 & 0103 & -0013 & 0085 & -0190 & -0137 & 0016 \\
\hline TP & -0101 & $0525 * *$ & -0151 & -0192 & -0330 & -0127 & -0079 & 0306 & -0185 & -0146 & -0200 & -0088 \\
\hline $\mathrm{TN}$ & -0038 & 0177 & -0035 & 0099 & 0295 & -0099 & 0012 & 0155 & -0042 & -0026 & -0095 & 0003 \\
\hline $\mathrm{N}: \mathrm{P}$ ratio & -0024 & 0106 & -0038 & -0285 & -0128 & -0121 & -0008 & 0083 & -0086 & -0193 & -0270 & -0009 \\
\hline $\mathrm{SD}$ & 0081 & 0192 & $0125 *$ & -0377 & 0361* & -0208 & 0057 & 0189 & 0162* & -0324 & -0143 & -0235 \\
\hline Chlorophyll & 0071 & 0256 & 0014 & 0478* & 0233 & -0032 & $0134 * *$ & 02474 & 0015 & $0516^{*}$ & $0442 *$ & -0035 \\
\hline Depth & -0004 & 0010 & 0035 & 0167 & -0105 & -0061 & 00208 & -0179 & 0013 & 02099 & -0202 & -0151 \\
\hline Area & -0058 & 0121 & -0025 & $0704 * *$ & 0157 & 0142 & -0026 & 0103 & -0111 & $0695^{*}$ & 0093 & -0053 \\
\hline Capacity & -0062 & 0057 & -0004 & 0425 & 0187 & 0101 & -0069 & 0021 & -0128 & 0514* & -0141 & -0081 \\
\hline HRT & 0004 & -0101 & 0001 & 0459* & -0122 & 0038 & -0016 & -0055 & -0092 & 0365 & -0052 & 0177 \\
\hline Rain & 0009 & 0085 & -0027 & NA & -0328 & 0052 & 0038 & -0085 & 0030 & NA & -0257 & -0037 \\
\hline Environment & -0039 & $0380 * *$ & -0075 & 0417 & -0076 & 0049 & 0048 & 0261* & -0062 & 0491* & -0344 & -0060 \\
\hline Space & $0113^{* *}$ & 0068 & -0064 & 0204 & 0049 & 0177 & $0138 * *$ & -0005 & -0030 & 0128 & -0041 & 0025 \\
\hline Environment|Space & -0058 & $0375 * *$ & -0072 & 0449* & -0077 & -0002 & 0028 & 0268* & -0060 & 0510* & -0344 & -0070 \\
\hline Space|Environment & $0120 * *$ & -0015 & -0060 & 0272 & 0050 & 0171 & $0133^{* *}$ & -0065 & -0027 & 0204 & -0040 & 0044 \\
\hline PCNM1 & $0267 * * *$ & $0242 *$ & -0029 & 0080 & -0060 & 0275* & $01327 * *$ & 0199* & 0004 & 0025 & 0033 & 0340* \\
\hline PCNM2 & $0175^{* * *}$ & 0181 & -0028 & 0216 & -0049 & -0059 & $02091 * * *$ & -0005 & 0004 & 0126 & -0071 & -0208 \\
\hline PCNM3 & 0016 & 0032 & -0022 & -0236 & 0249 & -0069 & 0013 & -0049 & -0056 & -0062 & 0251 & -0128 \\
\hline PCNM4 & -0013 & -0184 & 0001 & 0347* & 0101 & -0102 & 0010 & -0265 & 0035 & $0373 * *$ & 0000 & -0151 \\
\hline PCNM5 & 0016 & 0023 & -0108 & -0059 & 0070 & 0191 & 0104 & -0079 & -0042 & -0094 & -0069 & 0143 \\
\hline
\end{tabular}

Note: Significance was tested based on 999 permutations and marked in bold $*, \mathrm{P}<005$; **, $\mathrm{P}<001$; ***, $\mathrm{P}<0001$

Environment|Space, pure environmental factors; Space|Environment, pure spatial factors

\section{Figures}




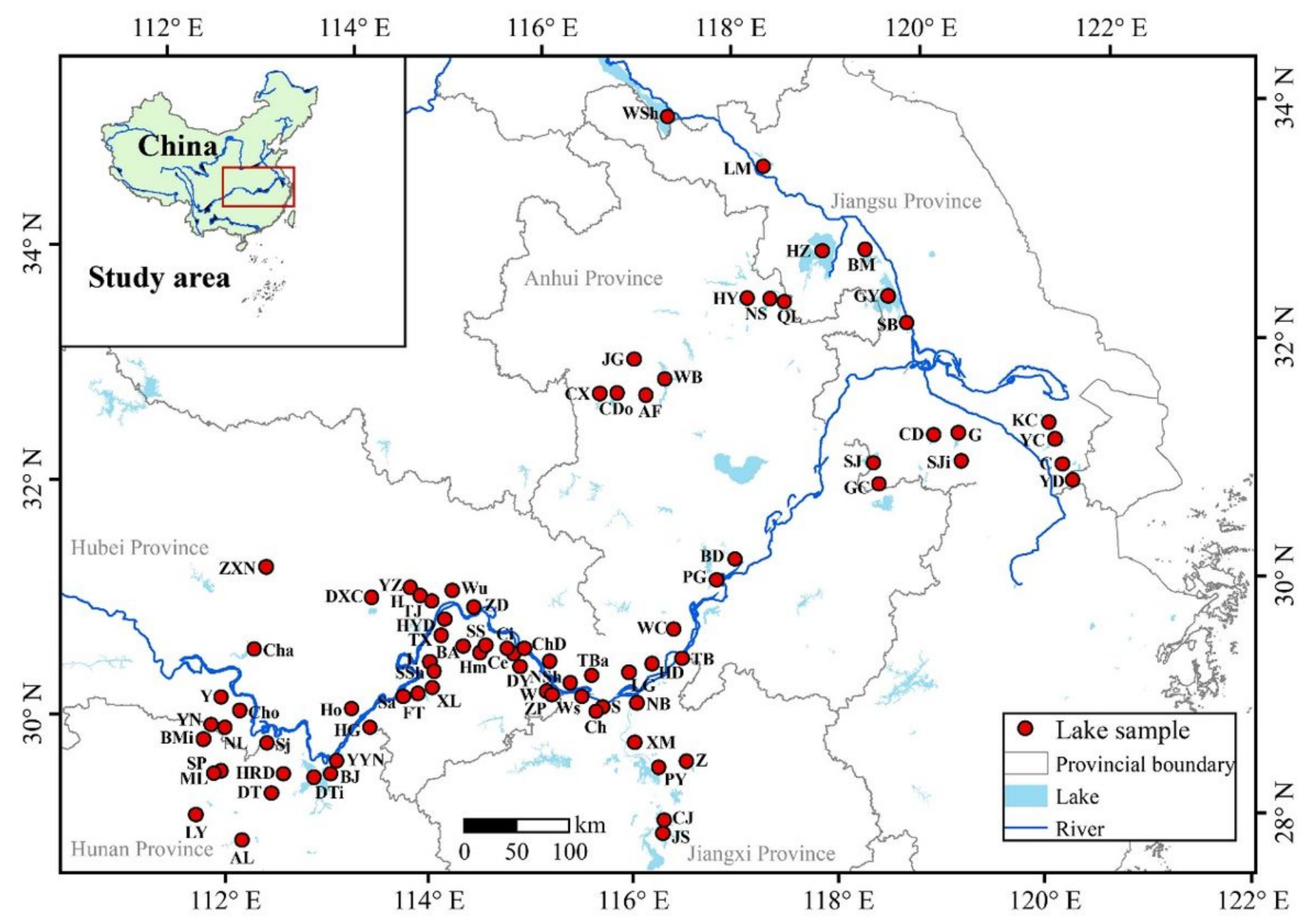

Figure 1

Sampling lakes and their locations along the MLYR floodplain 


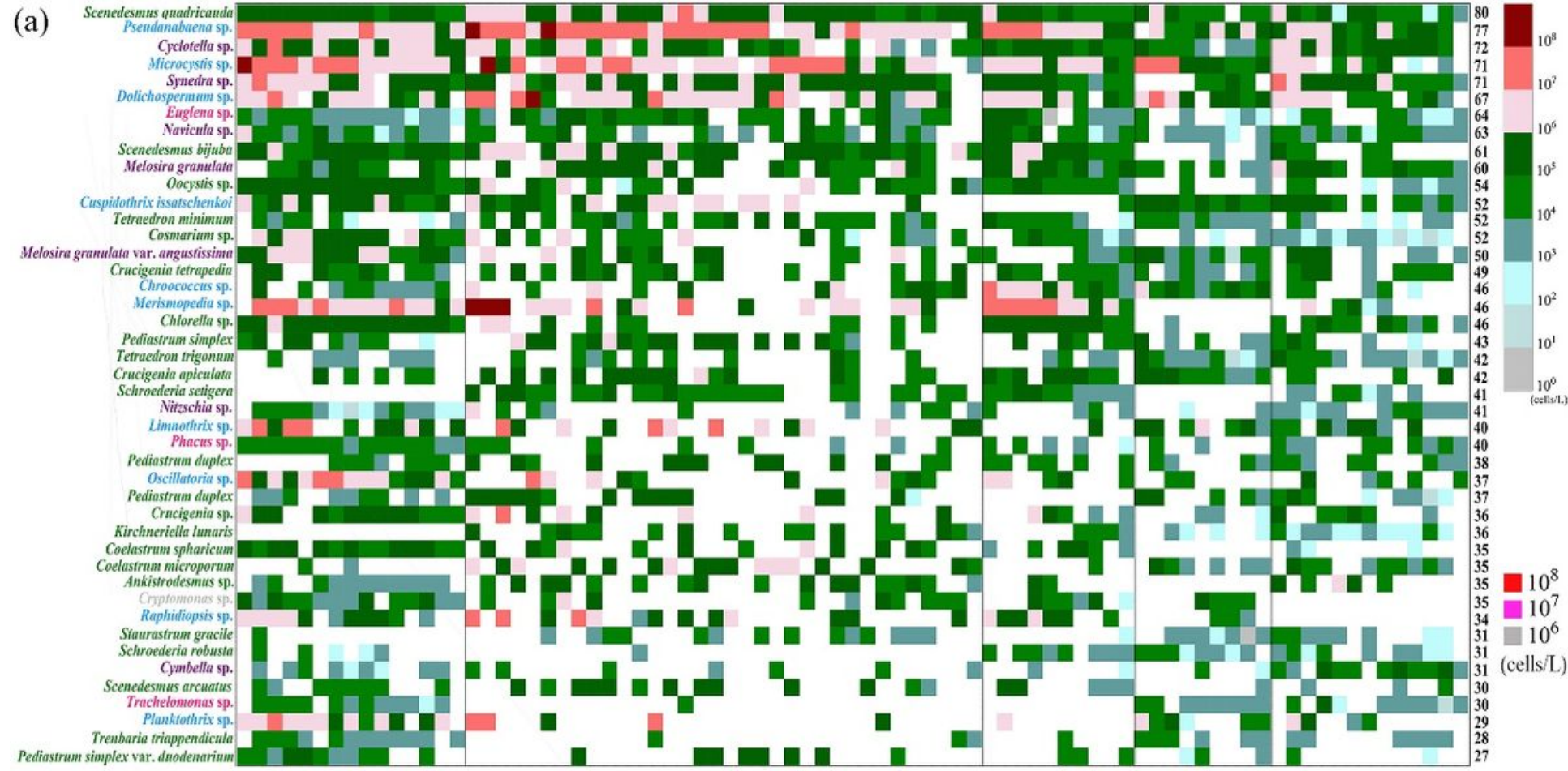

(b)

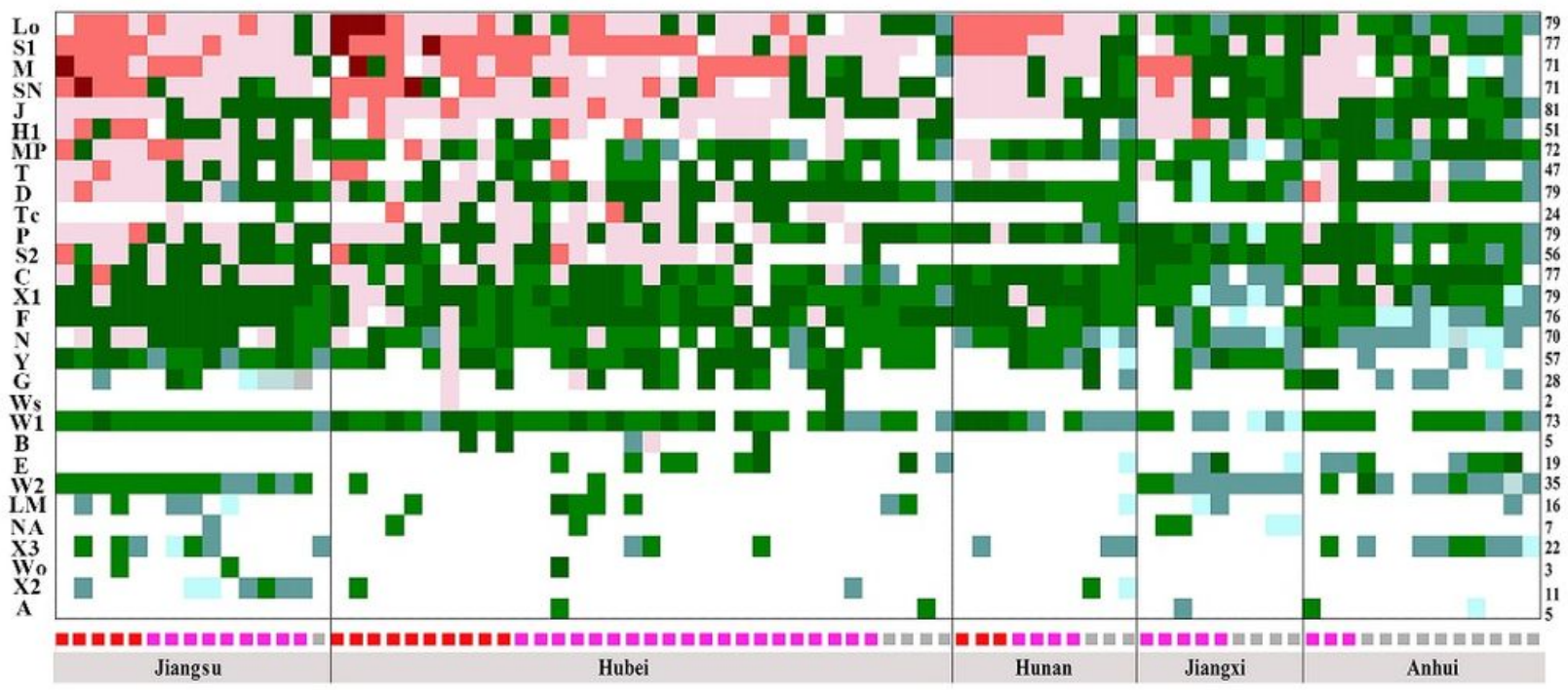

Figure 2

Mean relative abundance of taxonomic (a) and functional phytoplankton diversity (b) in MLYR plain lakes In (a), only infrageneric taxa occurred in over 1/3 lakes are shown; taxa belonged to Cyanophyta, Chlorophyta, Bacillariophyta, Euglenophyta, and Cryptophyta are marked in blue, green, crimson, pink, and grey colors Each of squares at the bottom represent one lake, and the colors are corresponding to the disparity in total phytoplankton abundance Numbers in the right indicate the occurrences of taxa shown in the lakes 

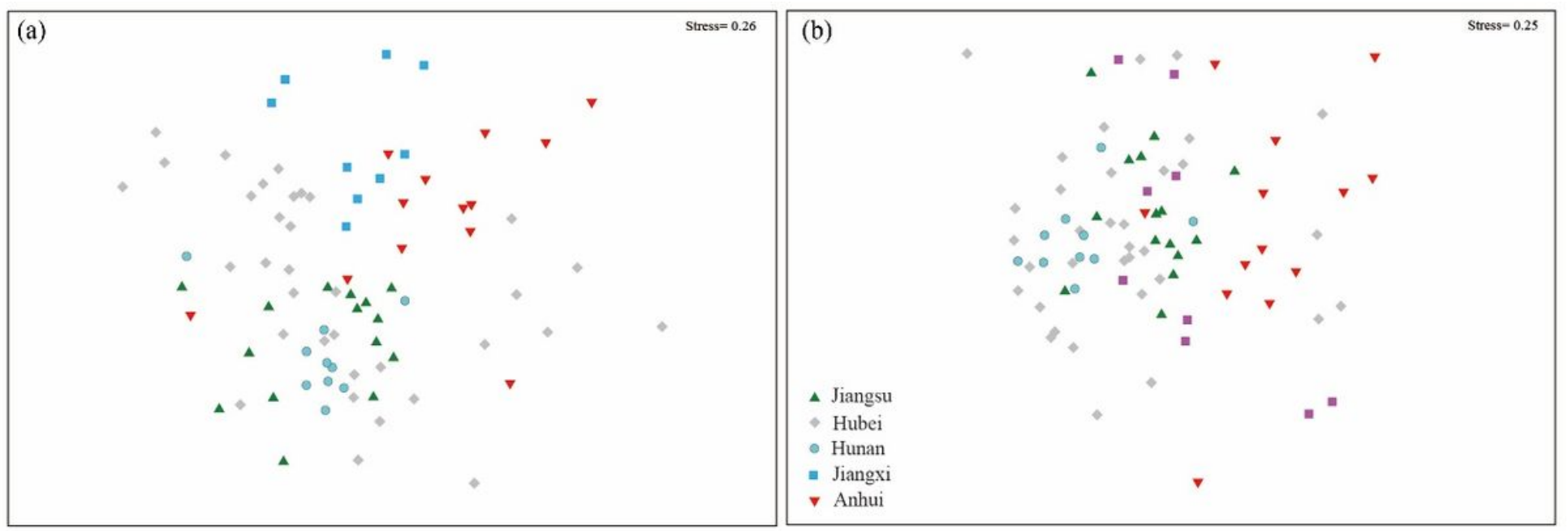

Figure 3

Non-metric multidimensional scaling (NMDS) ordination based on Bray-Curtis similarity of taxonomic (a) and functional compositions (b) of phytoplankton community Lake samples were colored based on their locations in different provinces

(a)

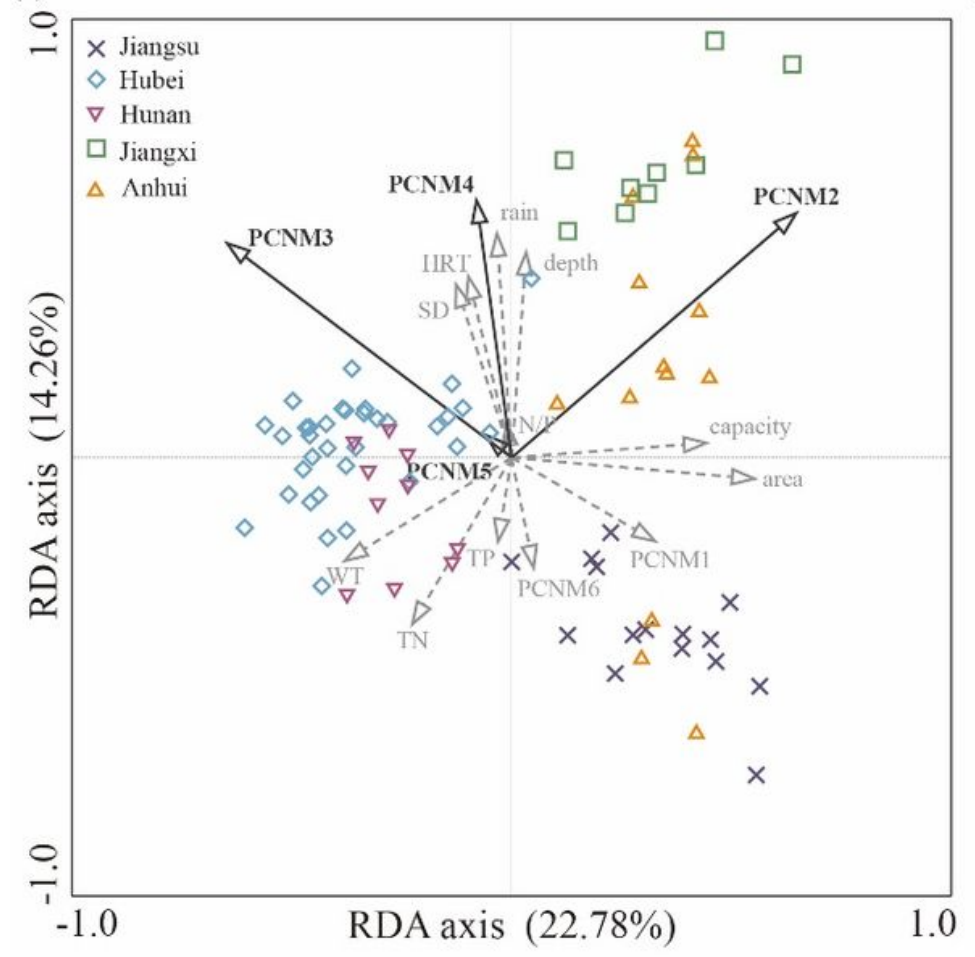

(b)

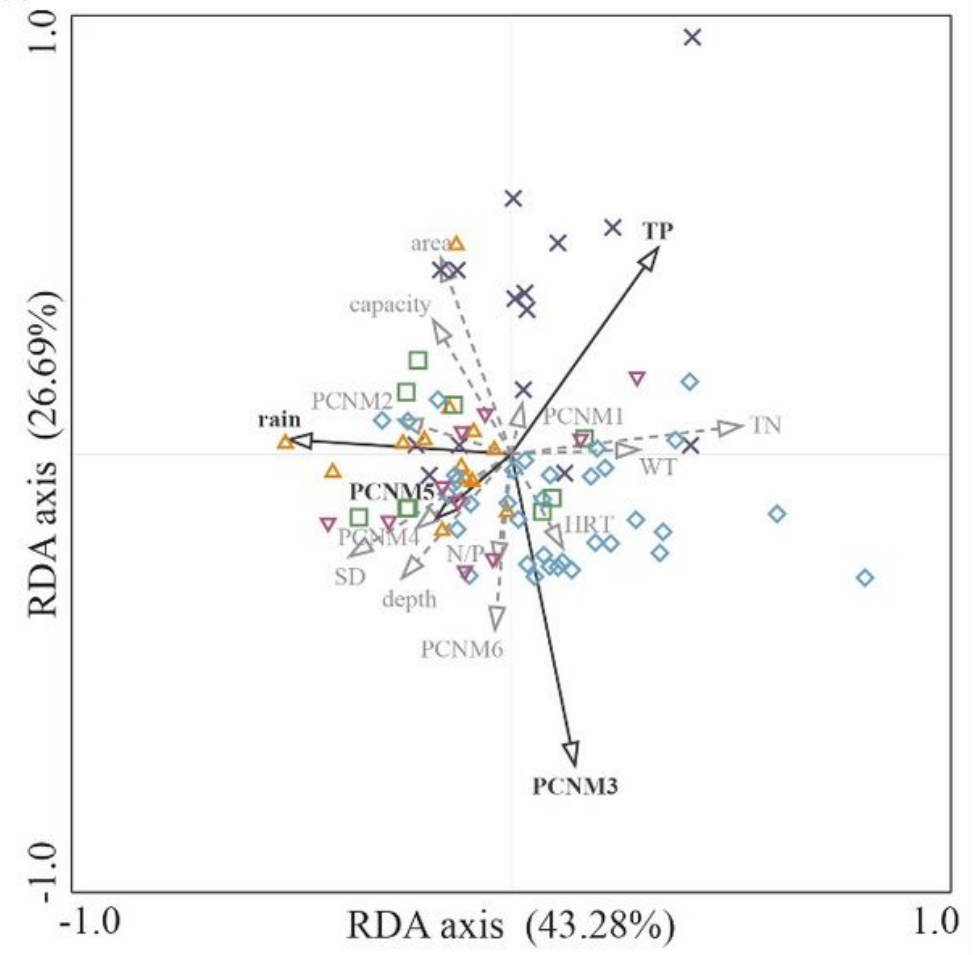

\section{Figure 4}

Ordination plots showing taxonomic (a) and functional composition (b) of phytoplankton community in relation to environmental and spatial factors Significant factors were indicated by solid lines 

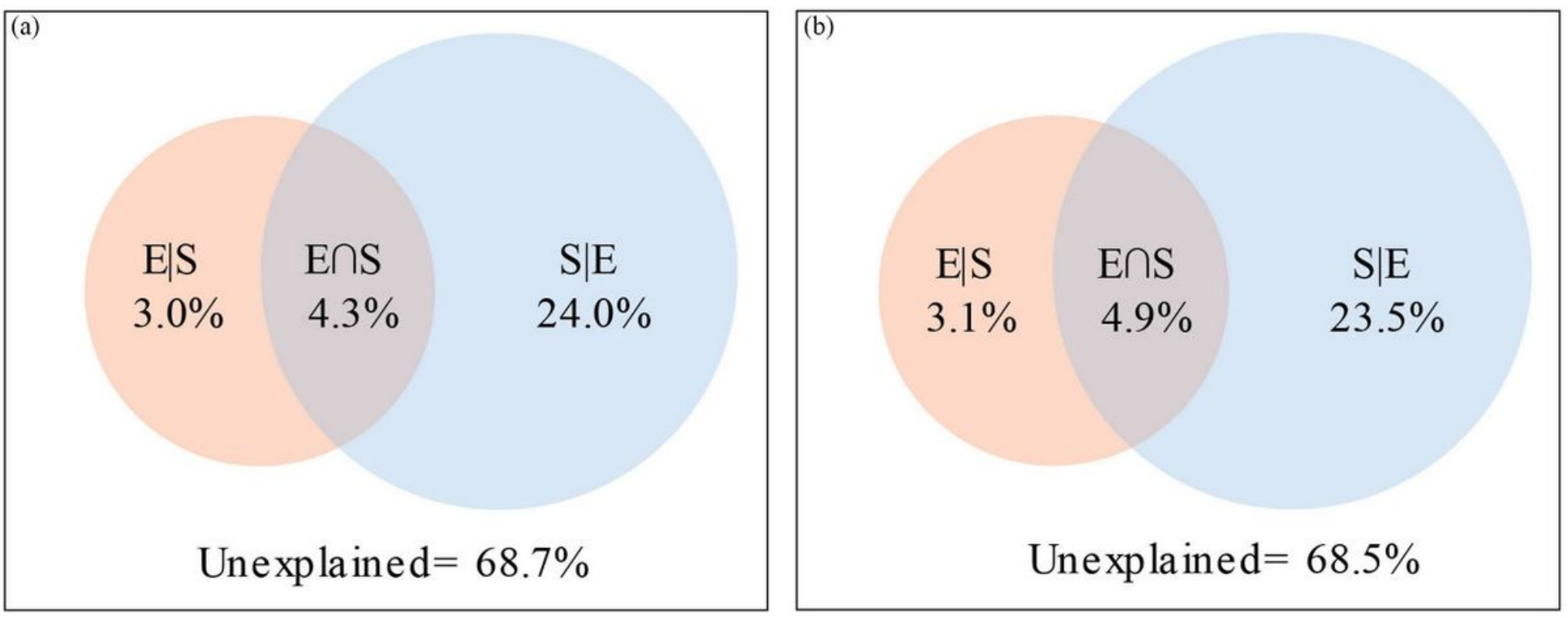

\section{Figure 5}

Variation partition analysis indicated the quantitative contributions to taxonomic (a) and functional composition (b) of phytoplankton community explained by environmental and spatial factors E|S, pure environmental variables; $\mathrm{S} \mid \mathrm{E}$, pure spatial variables; $\mathrm{E} \cap \mathrm{S}$, shared explained variations; unexplained variations =

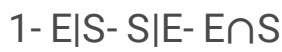

\section{Supplementary Files}

This is a list of supplementary files associated with this preprint. Click to download.

- Supplementarymaterials.docx 